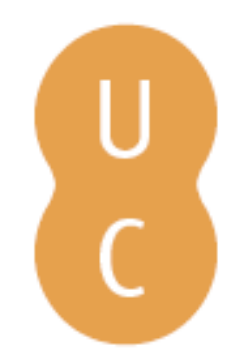

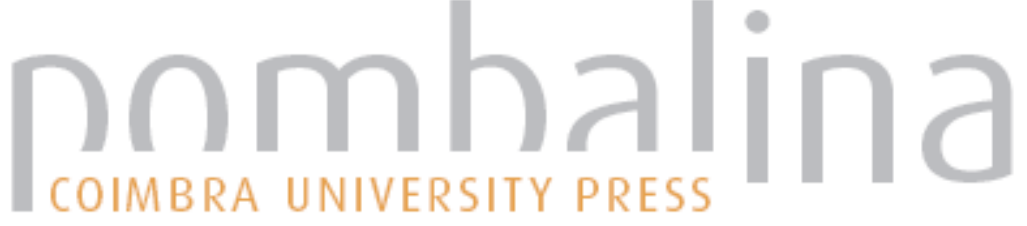

\section{Ortopedia, variantes da normalidade e problemas frequentes}

\author{
Autor(es): $\quad$ Alves, Cristina
}

Publicado por: Imprensa da Universidade de Coimbra

URL

persistente: URI:http://hdl.handle.net/10316.2/43128

DOI: $\quad$ DOI:https://doi.org/10.14195/978-989-26-1300-0_27

Accessed : $\quad$ 26-Apr-2023 12:23:03

A navegação consulta e descarregamento dos títulos inseridos nas Bibliotecas Digitais UC Digitalis, UC Pombalina e UC Impactum, pressupõem a aceitação plena e sem reservas dos Termos e Condições de Uso destas Bibliotecas Digitais, disponíveis em https://digitalis.uc.pt/pt-pt/termos.

Conforme exposto nos referidos Termos e Condições de Uso, o descarregamento de títulos de acesso restrito requer uma licença válida de autorização devendo o utilizador aceder ao(s) documento(s) a partir de um endereço de IP da instituição detentora da supramencionada licença.

Ao utilizador é apenas permitido o descarregamento para uso pessoal, pelo que o emprego do(s) título(s) descarregado(s) para outro fim, designadamente comercial, carece de autorização do respetivo autor ou editor da obra.

Na medida em que todas as obras da UC Digitalis se encontram protegidas pelo Código do Direito de Autor e Direitos Conexos e demais legislação aplicável, toda a cópia, parcial ou total, deste documento, nos casos em que é legalmente admitida, deverá conter ou fazer-se acompanhar por este aviso.

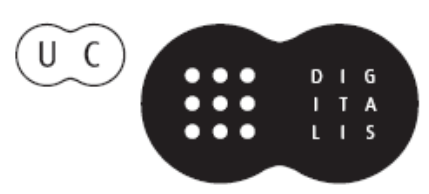




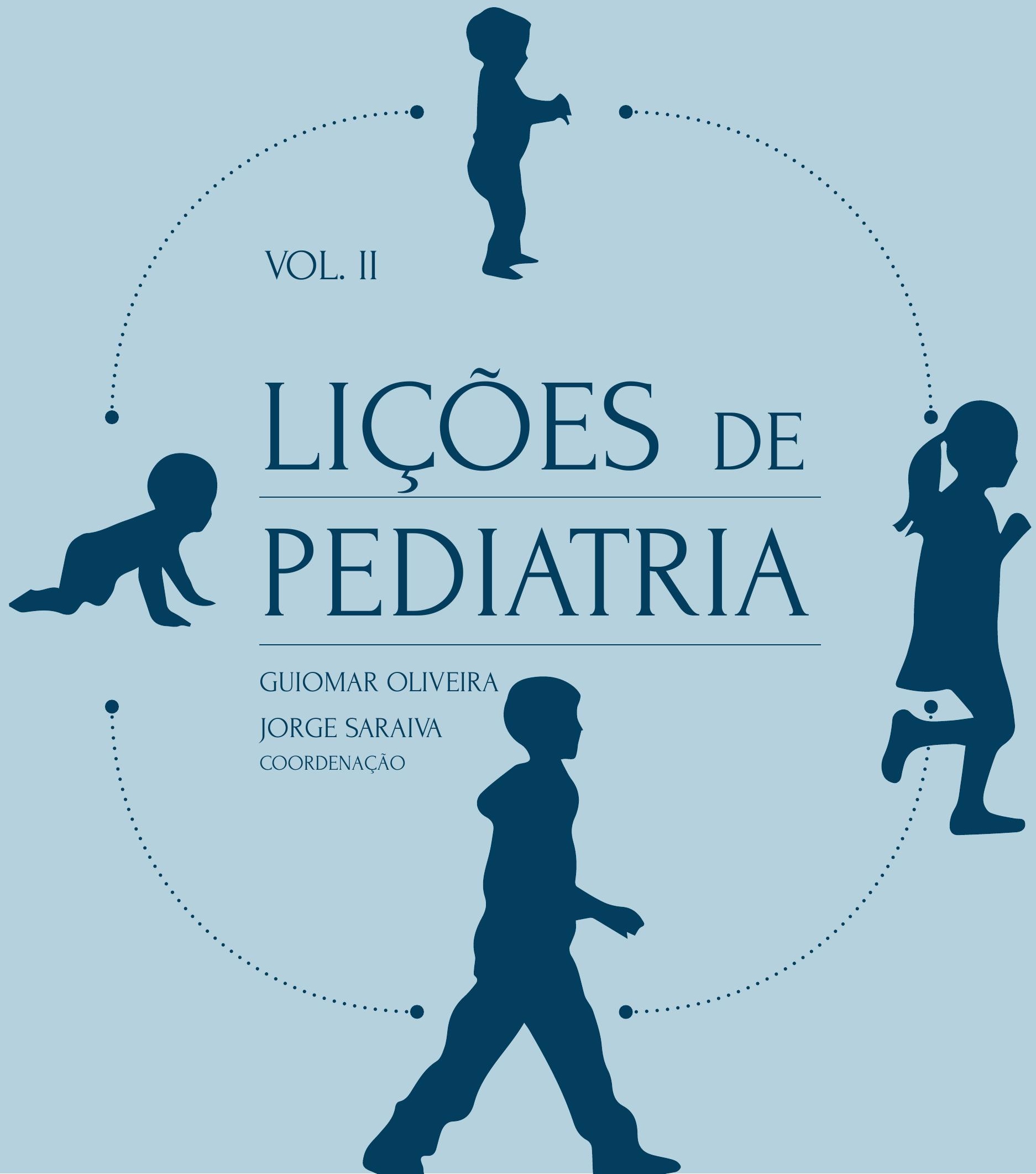


Capítulo 27.

Ortopedia, variantes da normalidade e problemas frequentes

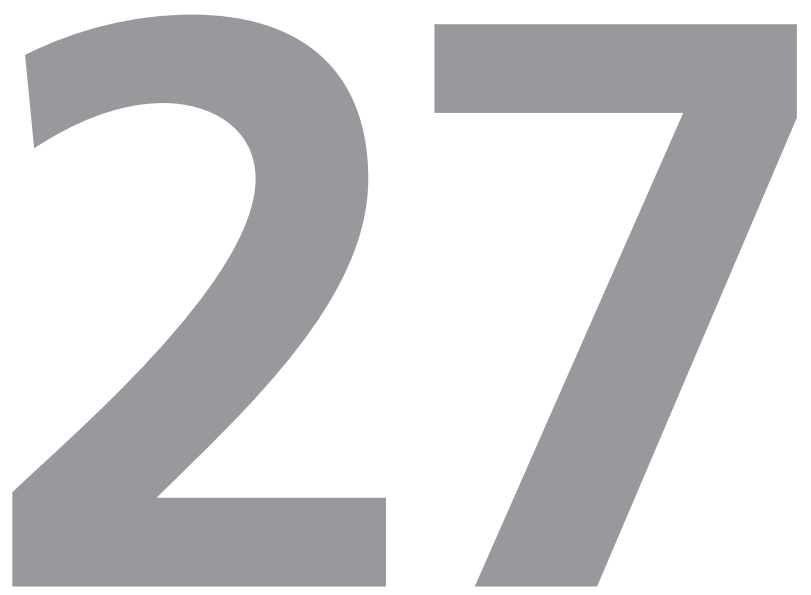

Cristina Alves 


\subsection{CONTEXTO}

O conceito de 'Ortopedia', surgiu em 1741, quando Nicholas Andry, Professor na Universidade de Paris, publicou o livro 'Orthopédie', onde apresentava uma teoria sobre a anatomia humana, a estrutura do esqueleto e as características do crescimento. Aí defendeu para o tratamento de deformidades músculo-esqueléticas na criança o exercício, a manipulação e a utilização de talas. Andry criou o termo'Orthopédie' pela junção de duas palavras gregas: 'Orthos', que significa 'recto' ou 'sem deformidade' e 'pais', que designa 'criança'. Dois anos depois, o livro foi traduzido para inglês com o título de "Orthopaedia".

A Ortopedia desenvolveu-se como especialidade médico-cirúrgica, dedicada à abordagem e tratamento das doenças e deformidades dos ossos, músculos, ligamentos e articulações. As especificidades da criança e as particularidades do esqueleto em crescimento promoveram o desenvolvimento da Ortopedia Pediátrica ou Infantil, uma vasta área da Ortopedia, dedicada à abordagem e tratamento da criança com problemas músculo-esqueléticos. É crucial que a maioria dos médicos tenha noções sobre o crescimento da criança, variantes da normalidade e problemas ortopédicos frequentes, de modo a que a referenciação das crianças que necessitam de cuidados ortopédicos possa ocorrer de forma correta e adequada, já que um diagnóstico precoce está frequentemente associado a melhor prognóstico.

As variantes da normalidade do desenvolvimento dos membros inferiores, tal como a marcha com progressão interna ou externa dos pés, o genu varum ou valgum, são motivos frequentes de preocupação das famílias e referenciação ao Pediatra ou Ortopedista.

\subsection{DESCRIÇÃO DO TEMA}

\subsubsection{Noções básicas de crescimento}

A formação dos ossos ocorre em três estadios: condensação das células mesenquimatosas que se tornam modelos para os futuros ossos; condrificação e ossificação intramembranosa ou endocondral.

A ossificação endocondral ocorre na maioria dos ossos. Durante o período fetal, os centros de ossificação primários desenvolvem-se na diáfise dos ossos longos. A ossificação ocorre primeiro sob o pericôndrio. Na cartilagem, as células hipertrofiadas degeneram. Em seguida, ocorre a invasão por vasos sanguíneos e o centro do modelo de cartilagem ossifica-se para formar o núcleo de ossificação primário. A ossificação endocondral continua na interface cartilagem-osso. Mais tarde, desenvolvem-se os núcleos de ossificação secundários nas extremidades dos ossos. A cartilagem, interposta entre os núcleos de ossificação primários e secundários transforma-se em placa de crescimento.

\section{Os núcleos de ossificação primários dos} ossos longos desenvolvem-se antes do nascimento, enquanto os núcleos de ossificação primários para os ossos pequenos, como a rótula e ossos de carpo e tarso, desenvolvem-se durante a infância. Os núcleos de ossificação secundários desenvolvem-se também durante a infância e fundem-se 


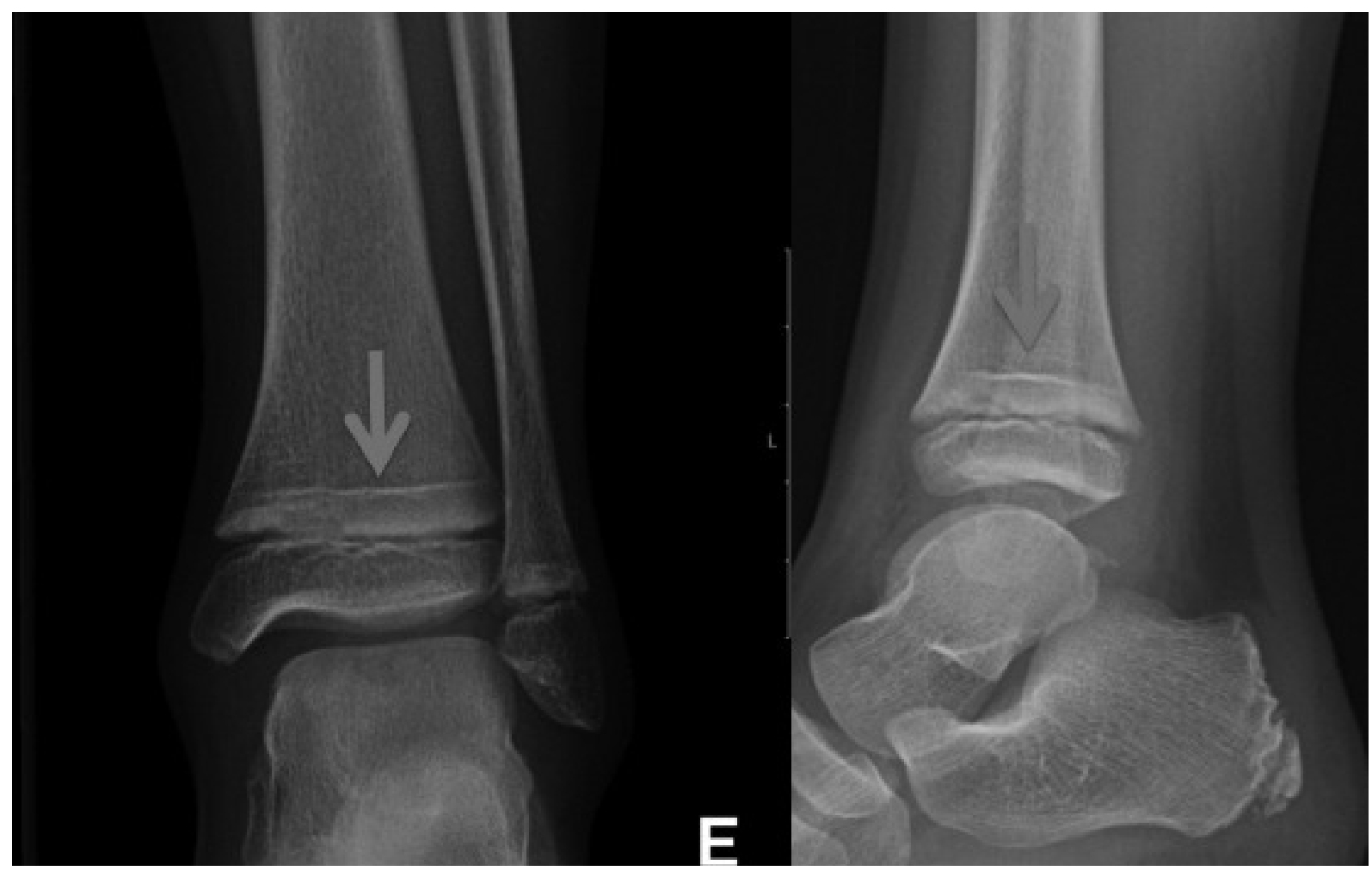

Figura 1. Linha de prisão de Harris observada na tíbia distal de criança de sete anos e sete meses após ter sofrido uma artrite séptica do tornozelo. A linha é paralela à fise de crescimento, inferindo-se assim que ocorreu um insulto em determinado momento, seguido de recuperação da atividade fisária. Também se observa linha de Harris no perónio distal. Imagem do autor.

com os núcleos de ossificação primários no final deste periodo, adolescência e início da vida adulta. Assim, e dado que a maturação óssea continua durante toda a infância e adolescência de forma razoavelmente ordeira, a extensão da ossificação documentada radiograficamente, constitui um padrão para avaliar a maturidade esquelética.

\section{Durante o período fetal é formado o osso} reticulado. Este tipo de osso caracteriza-se por ter pouca estrutura, apresentando um teor de colagénio elevado, e uma grande flexibilidade que se torna essencial para a moldagem no processo de descida pelo canal de parto na altura do nascimento. O osso reticulado é gradualmente substituído pelo osso lamelar durante a infância. A espessura cortical também aumenta durante toda a infância. Estas mudanças são fatores importantes na origem de padrões variáveis de lesões esqueléticas observadas durante a infância, adolescência e vida adulta. A espessura crescente, a estrutura lamelar e a proporção de cálcio ósseo mais elevada contribuem para dar grande resistência às forças de tensão, mas pouca flexibilidade.

A placa de crescimento dos ossos longos desenvolve-se entre os núcleos de ossificação primários e secundários. A função da placa de 
crescimento é determinar o crescimento longitudinal. Este processo é conseguido através de um sistema complexo de proliferação e maturação dos condrócitos, da produção da matriz óssea e mineralização, seguida de ossificação endocondral. As placas de crescimento dos ossos redondos, tais como os ossos do tarso ou corpos vertebrais, têm um potencial de crescimento mais limitado.

A placa de crescimento tem três zonas: a zona de reserva fica junto aos núcleos de ossificação secundários e é uma zona de relativa inatividade, que não participa no crescimento longitudinal do osso, mas produz matriz e tem funções de armazenamento; a zona proliferativa é a área de replicação das células cartilagíneas e de crescimento rápido, possibilitado pela alta taxa metabólica e pelo abundante suprimento de sangue, oxigênio, glicogénio; e a zona hipertrófica consiste em três subzonas (maturação, degeneração, e calcificação provisória).

A metáfise, sendo muito vascularizada, é o local onde ocorre a formação e a remodelação do osso. A matriz calcificada é removida, sendo formado osso fibroso que é posteriormente substituído por osso lamelar.

\section{Os problemas na placa de crescimento} constituem uma proporção significativa das doenças do sistema músculo-esquelético na criança. A placa de crescimento e a metáfise são os locais preferencialmente atingidos por infeções, neoplasias, fraturas e distúrbios metabólicos e endócrinos, que podem afetar o crescimento. Breves períodos de atraso de crescimento podem traduzir-se por linhas de prisão de Harris, que podem ser observadas em radiografias. (Figura 1).
Durante o crescimento, as proporções do corpo assumem gradualmente a forma adulta. O crescimento dos membros superiores ocorre mais cedo do que o dos inferiores. Nos membros inferiores são os pés que crescem mais precocemente. Nos primeiros dois anos de vida, o crescimento rápido ocorre no tronco, enquanto na adolescência acontece sobretudo nos membros inferiores.

A velocidade de crescimento é superior nos primeiros anos de vida, declina depois e aumenta na puberdade. Uma criança atinge cerca de três quartos da sua altura adulta por volta dos nove anos de idade. As zonas de crescimento são variáveis: no membro superior, o crescimento é mais rápido nas regiões do ombro e punho; no membro inferior o crescimento é mais rápido na região do joelho.

A taxa de crescimento dos tecidos varia com a idade. A gordura subcutânea desenvolve-se durante o primeiro ano, fornecendo reserva nutricional e protegendo contra o frio e lesões. O depósito desta gordura também disfarça o arco longitudinal do pé, contribuindo para uma aparência de pé plano, que é normal nos primeiros anos de vida. Para além do pé plano, outras variações transitórias do crescimento da criança, como a marcha com progressão interna ou externa dos pés e o genu varum ou valgum podem ser confundidas com alterações patológicas. A maioria destas situações, que constituem variantes da normalidade, resolve-se com o tempo e raramente necessita de qualquer tratamento.

No período da adolescência, e até à maturidade esquelética, podem ocorrer algumas doenças como a escoliose ou a epifisiólise 
femoral superior. A determinação da maturidade esquelética e a estimativa do crescimento global, em determinada fase, são importantes na abordagem e para a decisão terapêutica em diversos contextos, desde a assimetria de comprimento dos membros à escoliose. A estimativa da idade/maturidade óssea pode se obtida por diversos métodos, a selecionar consoante a situação concreta, tais como: radiografias da mão e do punho não dominantes (interpretação de acordo com o atlas de Greulich-Pyle); radiografia do cotovelo (baseado na ossificação da apófise olecraneana); estádio de Tanner (ver lição de adolescência); sinal de Risser (extensão da ossificação da crista ilíaca em radiografia com incidência anteroposterior).

As doenças que afetam o sistema músculo-esquelético e causam limitação das atividades são frequentes na criança e nalgumas a sua prevalência tem aumentado, já que as crianças têm maior probabilidade de sobreviver hoje a doenças que eram fatais no passado (quadro 1).

\begin{tabular}{|l|l|}
\hline Doença & $\begin{array}{l}\text { Prevalência } \\
\text { estimada/1000 }\end{array}$ \\
\hline Paralisia Cerebral & 2.5 \\
\hline Trissomia 21 & 1.1 \\
\hline $\begin{array}{l}\text { Displasia do desenvolvimento } \\
\text { da anca }\end{array}$ & 1.0 \\
\hline Pé boto & 1.0 \\
\hline Distrofia muscular & 0.06 \\
\hline
\end{tabular}

Quadro 1. Prevalência estimada de problemas ortopédicos na criança.

\subsubsection{Abordagem da criança com suspeita de problema músculo-esquelético}

A avaliação clínica é o primeiro e mais importante passo nesta abordagem. Cada situação requer um diagnóstico, mas apenas algumas necessitam tratamento. A avaliação da criança é muitas vezes difícil, no que concerne à realização da história clínica e exame objetivo. Lidar adequadamente com a família é crucial.

\section{A deformidade, a alteração da função} e a dor são as grandes categorias de queixas que motivam Consulta em Ortopedia Pediátrica. Aqui como em todos os quadros pediátricos, é essencial considerar a idade da criança.

As deformidades posicionais como problemas rotacionais, pés planos, e alterações do eixo dos membros inferiores são preocupações comuns, mas raramente têm significado patológico. Problemas mais significativos, tais como as deformidades congénitas e de causa neuromuscular, exigem uma avaliação cuidadosa, devendo ser estabelecido quando ocorreu o seu início. Se a família tiver fotografias prévias da criança, estas podem auxiliar a estabelecer a evolução da doença.

A alteração da função pode ser atribuída à presença de deformidade, fraqueza muscular, ou dor. A expressão da dor depende da idade: o lactente apresenta-se geralmente irritado e evita mobilizar a região dolorosa, sendo aparente uma pseudoparalisia do membro; a criança pode apresentar diminuição da função, evitar mover a parte afetada, ou queixar-se de desconforto; o(a) adolescente geralmente verbaliza a queixa de dor. 
A dor é um sintoma importante e evoca diagnósticos que podem traduzir situações de trauma, inflamação, infeção ou patologia neoplásica. É frequente atribuir o problema musculo-esquelético da criança ao trauma, mas importa salientar que este é um evento frequente em pediatria, pelo que a história clínica e o exame objetivo devem ser suficientemente criteriosos para excluir patologia de maior gravidade, como as infeções ou as doenças neoplásicas.

A história prévia da criança é essencial, para compreender o seu estado de saúde geral e contextualizar o problema actual. É importante conhecer factos referentes a: história pré e perinatal; idade de aquisição das etapas chave do neurodesenvolvimento; intuição e preocupações dos pais; história familiar: se outros familiares têm problemas semelhantes.

\subsubsection{Exame físico}

É importante aproximar-se da criança de forma amigável e gentil e, em alguns casos, pode ser útil começar por observá-la no colo da mãe. Há que tranquilizar a criança. Se a criança permanecer assustada ou pouco colaborante, pode-se começar por observar um dos pais ou irmãos. Se a criança não quiser caminhar, os pais podem levá-la para um lado da sala e afastar-se depois, já que ela irá geralmente caminhar ou correr de volta para eles. Se a criança tem dor, o local doloroso deve ser examinado por último.

Um exame geral deve preceder o exame dirigido à queixa principal. Assim, não se ignoram outros problemas ortopédicos e adquire-se uma visão global do sistema músculo-esquelético, necessária para compreender o problema específico. Por exemplo, o conhecimento da presença de laxidez ligamentar generalizada é valioso na avaliação de um pé plano. A criança deve ser observada pela frente, pelos lados e por detrás e o exame físico deve incluir: inspeção geral: olhar para a configuração corpo, simetria, proporções e presença de deformidades; pélvis: colocar as mãos sobre as cristas ilíacas e localizar as espinhas ilíacas antero-superiores e verificar se estão niveladas; pedir à criança para levantar uma perna de cada vez, para verificar se existe fraqueza dos músculos abdutores; coluna: observar o alinhamento sagital da coluna e avaliar a simetria torácica e lombar e pedir à criança para se inclinar para a frente, mantendo os joelhos em extensão, de forma a verificar eventual assimetria ou evidência de escoliose (manobra de Adams); marcha: observar o andar, primeiro com a marcha normal e, em seguida, se possível, na ponta dos pés e em calcanhares. Procurar assimetria, irregularidade da cadência, ou fraqueza muscular; mobilidade articular: geralmente, o arco de movimento é maior na infância e diminui com a idade; avaliação de deformidades: em referência aos planos do corpo (frontal, sagital, transverso), na posição anatómica. A maioria das deformidades são multiplanares e não ocorrem apenas num dos planos; palpação: procurar massas e pontos dolorosos.

\subsubsection{Variantes da normalidade}

\subsubsection{Problemas torsionais dos membros inferiores}

Os problemas torsionais, que as famílias verbalizam como 'andar com os pés para dentro' 


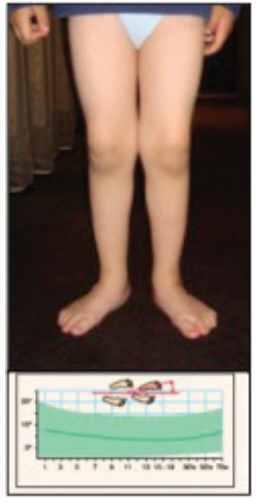

Figura 2. O ângulo de progressão do pé é estimado pela observação da criança a caminhar. A variabilidade da normalidade é mostrada a verde.

ou 'pés para fora' são, na sua maioria, variantes da normalidade, que não carecem de qualquer tratamento, mas causam ansiedade significativa à família.

Versão, em ortopedia, é um termo que descreve variações normais de rotação do membro, enquanto torsão significa versão além de $\pm \mathbf{2}$ desvios-padrão da média, sendo 'anormal' e correspondendo a uma «deformidade». De salientar que o membro inferior gira externamente com a idade, com diminuição da anteversão femoral e aumento da versão externa da tíbia.

O membro inferior gira em sentido medial (interno) durante a sétima semana fetal, para conduzir o hallux para a linha média. Com o crescimento, a anteversão femoral diminui para cerca de $30^{\circ}$ ao nascimento e $10^{\circ}$ na maturidade, podendo ser maior no sexo feminino e em algumas famílias. Com o crescimento, a tíbia gira lateralmente de cerca de $5^{\circ}$ ao nascimento para cerca de $15^{\circ}$ na maturidade esquelética. Porque o

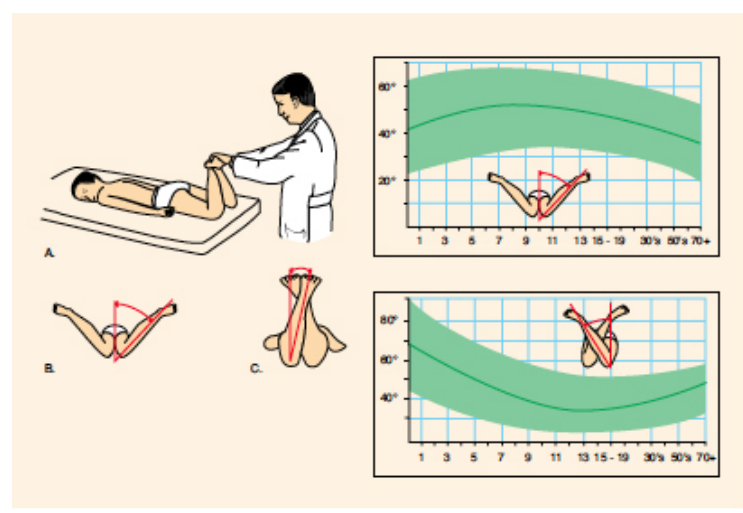

Figura 3. Rotações interna e externa das ancas avaliadas com a criança em decúbito ventral. A variabilidade da normalidade é mostrada a verde.

crescimento está associado com rotação lateral, é expectável que a anteversão femoral e a torção tibial melhorem com o tempo. Em contraste, a torção lateral da tíbia geralmente agrava com o crescimento.

$\mathrm{Na}$ abordagem dos problemas torsionais, é necessário estabelecer um diagnóstico correto e lidar de forma eficaz com a família.

A história é importante na avaliação da repercussão deste problema e na exclusão de outros. É importante ter conhecimento do seu início, da gravidade, da limitação funcional e do tratamento prévio. A história do neurodesenvolvimento é essencial, para excluir patologia neuromuscular. É importante saber a história familiar, dado que os problemas rotacionais são geralmente herdados.

A observação do perfil rotacional permite obter as informações necessárias para estabelecer o nível e a gravidade de qualquer problema de torção na criança. Para isso é necessário avaliar quatro aspetos: marcha e corrida da criança 


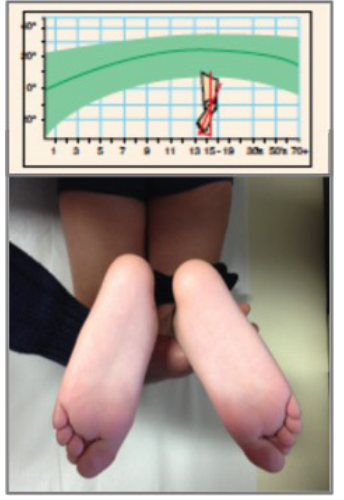

Figura 4. A. Em decúbito ventral, e deixando o pé cair para a sua posição de repouso natural, é possível verificar o ângulo coxa-pé e a forma do pé.

(figura 2): estimar o ângulo de progressão do pé (diferença angular entre o eixo do pé e a linha de progressão durante a marcha); versão femoral (figura 3): medir a rotação interna e externa da anca com a criança em decúbito ventral e os joelhos flectido a $90^{\circ}$ (ambos os lados devem ser avaliados simultaneamente, sendo a rotação interna geralmente inferior a $70^{\circ}$ ); torção tibial (figura 4): avaliar o ângulo coxa-pé (diferença angular entre os eixos do pé e da coxa) com a criança em decúbito ventral e o joelho fletido em ângulo reto. O ângulo coxa-pé mede o estado de rotação tibial; avaliar o pé para a presença de aduto (figura 5): o bordo lateral do pé é normalmente reto (figura 6).

Realizado o exame geral e o perfil rotacional, é geralmente possível estabelecer a causa da deformidade rotacional.

A marcha com 'pés para dentro', frequentemente relacionada com anteversão femoral
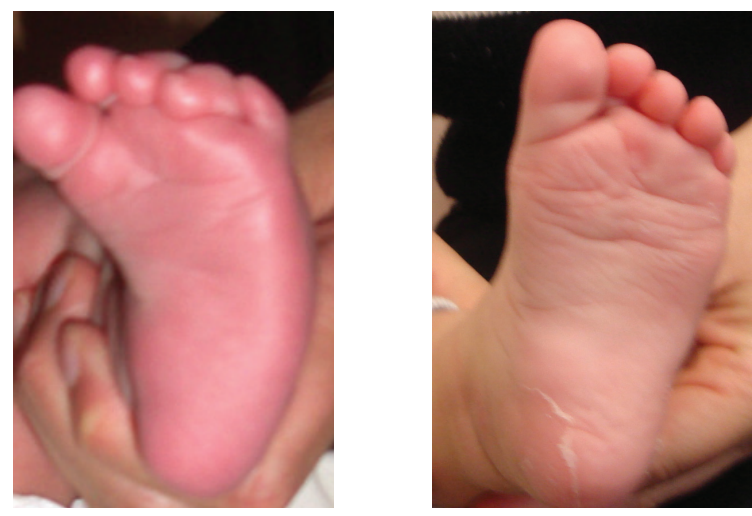

Figura 5. Pé aduto, com

Figura 6. Pé normal, com bordo externo curvo.

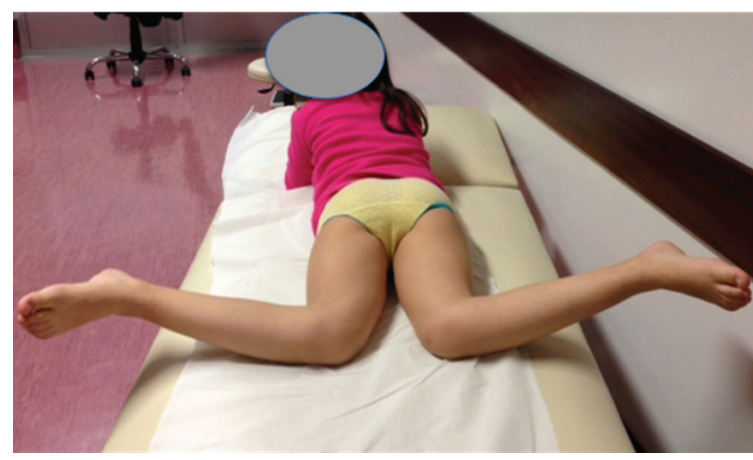

Figura 7. Menina de seis anos com anteversão femoral exagerada.

aumentada e ou torção tibial interna, corrige-se geralmente de forma espontânea, ao longo do tempo.

A anteversão femoral exagerada (figura 7) é mais acentuada entre os quatro e os seis anos de idade, resolvendo-se progressivamente. Estas crianças gostam de se sentar em $\mathbf{W}$ e têm uma rotação interna das ancas superior a $70^{\circ}$. Contudo, 


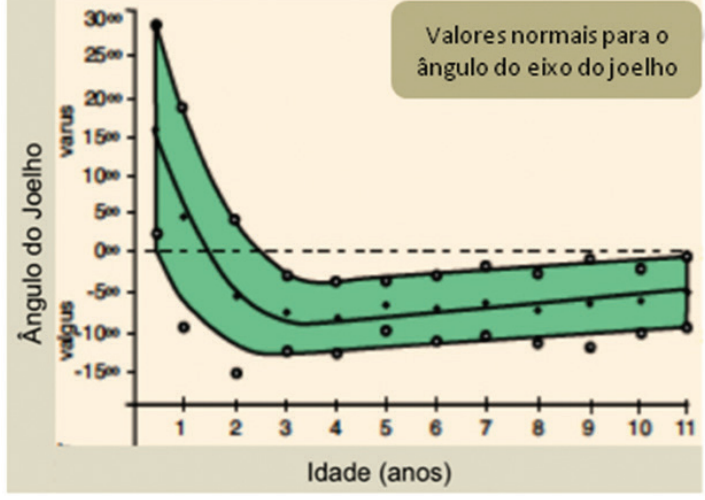

Figura 8. Os valores normais para o ângulo do eixo do joelho, com \pm 2 desvios-padrão (adaptado de Heath e Staheli, 1993).

qualquer tentativa para controlar a forma como a criança caminha, se senta ou dorme, contribui apenas para gerar frustração e conflito entre a criança e os pais. Sapatos ortopédicos, palmiIhas ou talas noturnas são ineficazes e não têm qualquer benefício a longo prazo.

Enquanto a torção tibial interna melhora com o tempo, a torção tibial externa tende a agravar e pode estar associada a dor no joelho, que surge na articulação patelofemoral e é presumivelmente causada pelo desalinhamento do joelho. Este fenómeno é mais acentuado quando a torção tibial externa se associa a torção femoral interna, produzindo um 'síndrome do mau-alinhamento'.

\section{Genu varum e genu valgum}

Genu Varum (joelho varo) e genu valgum (joelho valgo) são deformidades do plano frontal do joelho, em que o ângulo de alinhamento dos joelho se encontra \pm 2 desvios padrão desviado da média (Figura 8). As variações que se encontram

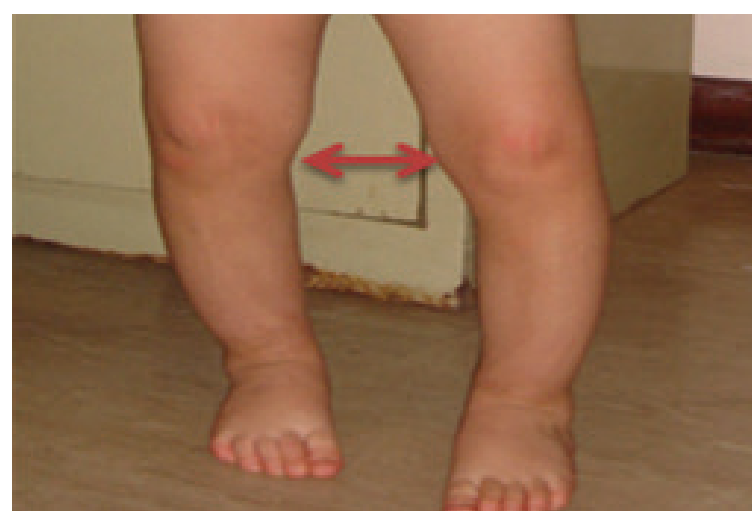

Figura 9. Joelho varo (genu varum): observa-se aumento da distância intercondiliana (entre os côndilos femorais mediais).

no intervalo normal são fisiológicas. O intervalo da normalidade para o ângulo de alinhamento do joelho altera-se com a idade.

No segundo ano de vida, é frequente o genu varum (Figura 9), enquanto o genu valgum é comum pelos três a quatro anos (Figura 10).

Na avaliação de uma criança com genu varum ou valgum é importante estabelecer o início da deformidade, se houve lesão ou doença precedente, se a deformidade é progressiva, se existem fotografias antigas ou radiografias disponíveis para rever, qual a saúde geral da criança, se a dieta é adequada e se existem outros membros da família afetados.

Perante a suspeita de um desvio do eixo subjacente a uma alteração patológica, será de realizar uma radiografia anteroposterior extra-longa dos membros inferiores, preferencialmente em carga. Se a criança tem uma deformidade generalizada, será necessário realizar exames laboratoriais, 


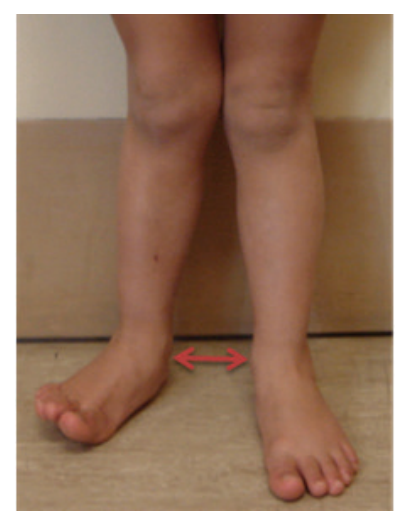

Figura 10. Joelho valgo (genu valgum): observa-se aumento da distância intermaleolar (entre maléolos tibiais mediais).

incluindo hemograma e doseamentos de cálcio, fósforo, fosfatase alcalina e creatinina.

\subsubsection{Pé plano}

O pé plano caracteriza-se por uma grande área de contato plantar. Está geralmente associado a um calcanhar valgo e a uma redução na altura do arco longitudinal. Pode ser fisiológico ou patológico. O fisiológico é flexível e constitui uma variante da normalidade; o patológico apresenta alguma rigidez, e, geralmente, necessita de tratamento.

O pé plano flexível ou fisológico está presente em quase todas as crianças, e em cerca de $15 \%$ dos adultos. O pé plano é muitas vezes familiar, sendo mais frequente nas sociedades em que as pessoas usam sapatos, nos obesos e nos indivíduos com laxidez articular generalizada.

Em ortostatismo, o pé encontra-se plano e o calcanhar pode mostrar valgo. O arco reaparece quando a criança se coloca em pontas dos dedos, observando-se uma concomitante varização do calcanhar (Figura 11).
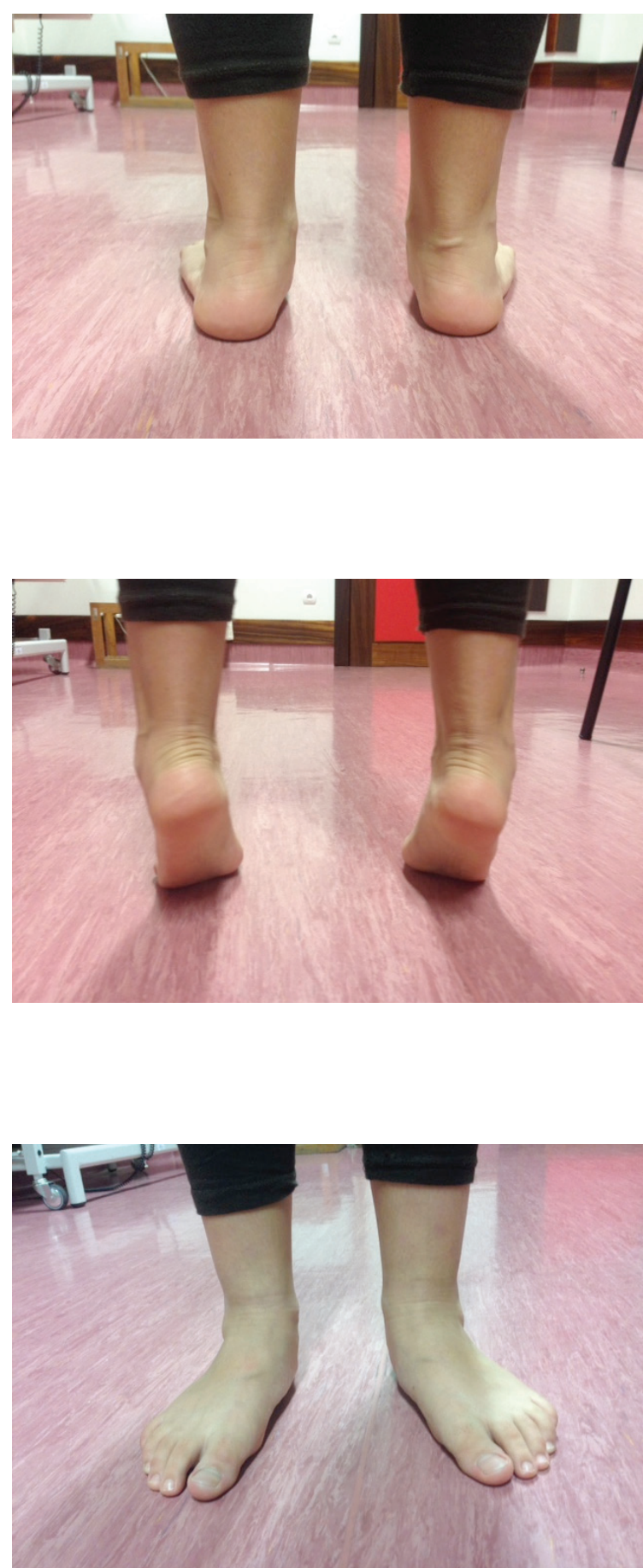

Figura 11. Pé plano flexível, que não necessita qualquer tratamento. 


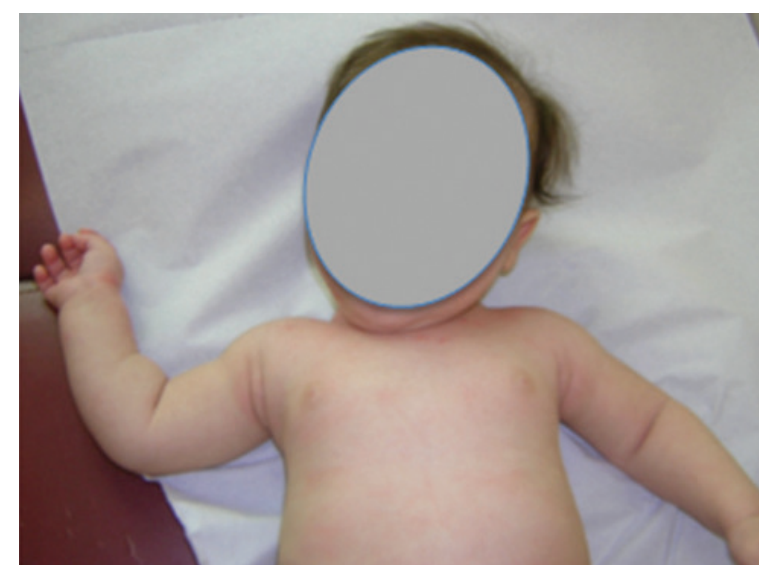

Figura 12. Torcicolo congénito.

O pé plano flexível não requer tratamento, nem é fonte de incapacidade funcional.

A seleção dos sapatos é uma preocupação das famílias, educadores e profissionais de saúde. O sapato deve proteger o pé de traumatismos e de variações de temperatura. Os melhores sapatos são aqueles que menos interferem com a função e melhor mimetizam o estado de pés descalços. Devem estar bem ajustados, para evitar quedas e compressão dos dedos.

\subsubsection{Problemas ortopédicos frequentes}

\subsubsection{Torcicolo congénito}

O torcicolo afecta $0,4 \%$ dos recém-nascidos e resulta do encurtamento unilateral do esternocleidomastoideu. Ocasionalmente, pelas duas a três semanas de idade pode detetar-se uma tumoração palpável e indolor no esternocleidomastoideu, com cerca de um a três cm de diâmetro. A cabeça encontra-se inclinada e flectida para o lado da tumoração (Figura 12).
O torcicolo persiste geralmente até ao ano de idade.

A etiologia do torcicolo não está completamente esclarecida. O exame clínico é geralmente suficiente para estabelecer o diagnóstico. A ecografia e a ressonância magnética cervical devem ser realizadas em raros casos selecionados.

O tratamento do torcicolo é essencialmente conservador, geralmente por fisioterapia, devendo os pais também receber instruções que lhes permitam realizar fisioterapia parental no domicílio. O alongamento manual controlado é seguro e eficaz no tratamento do torcicolo muscular congénito em crianças com idade de inferior a um ano.

As indicações para tratamento cirúrgico são muito raras. A fibrose do esternocleidomastoideu desaparece espontaneamente, na grande maioria dos lactentes.

\subsubsection{Escoliose}

A escoliose é uma deformidade complexa da coluna, que atinge os planos frontal, transverso e sagital. Define-se como uma curva com ângulo superior a $10^{\circ}$ numa radiografia extralonga da coluna, realizada no plano frontal. Na criança em crescimento, estas curvas podem progredir de forma significativa.

A escoliose classifica-se consoante a idade de início como escoliose infantil, se ocorre em crianças menores de três anos de idade; escoliose juvenil, se ocorre em crianças dos quatro aos nove anos, e escoliose do adolescente, se ocorre em pessoas com mais de dez anos. Atualmente define-se a escoliose como precoce ou tardia, consoante ocorre antes ou depois de cinco anos de idade. 


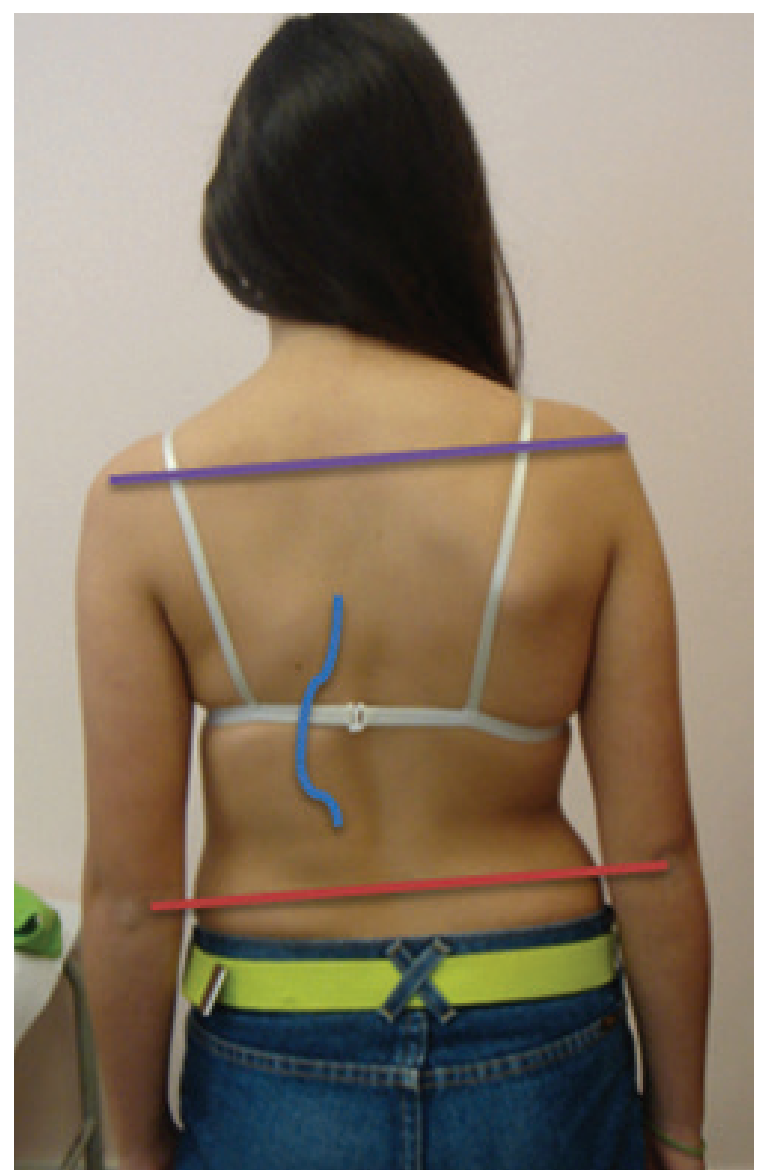

Figura 13. Sinais clínicos sugestivos de escoliose: ombros desnivelados, curvatura da coluna vertebral, cintura pélvica assimétrica.

A maioria dos casos de escoliose (80\%) é idiopática, já que não é identificada qualquer causa. Os restantes $20 \%$ ocorrem no contexto de síndromes (escoliose síndrómica) ou anomalias congénitas da coluna vertebral (escoliose congénita). No exame clínico, é essencial excluir ou confirmar estigmas sugestivos de síndrome de Marfan ou de neurofibromatose. É importante determinar se a criança tem dor, já que as formas dolorosas sugerem etiologia inflamatória, infeciosa ou neoplásica.

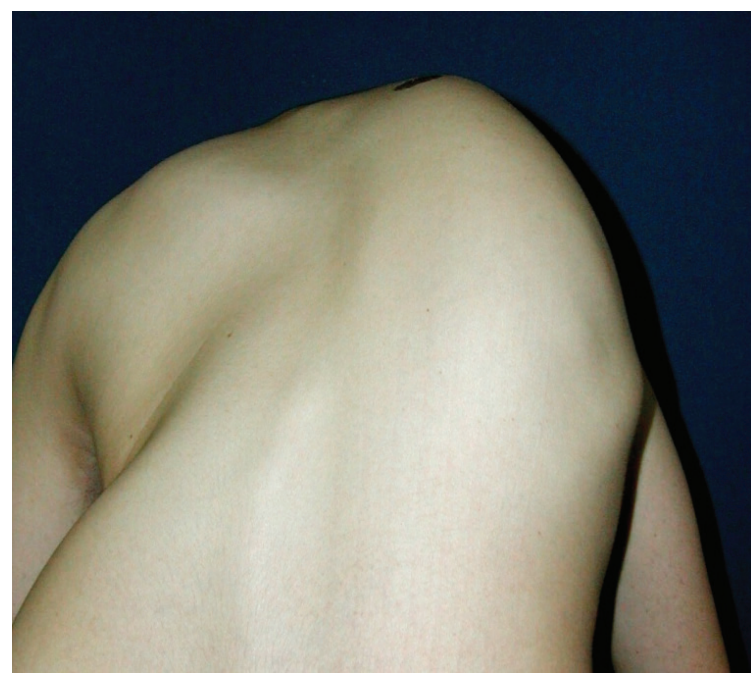

Figura 14. Proeminência costal aquando da realização da manobra de Adams, sugestiva de escoliose.

É fundamental perceber a idade de início da deformidade da coluna e estimar o potencial de progressão da curva, uma vez que este será tanto maior quanto menor for a maturidade esquelética da criança.

É importante realizar um exame neurológico, incluindo as caraterísticas da marcha, e avaliar o comprimento dos membros e a marcha. Há que verificar a simetria do tronco e das cinturas escapular e pélvica (Figura 13).

A manobra de Adams consiste em pedir ao doente para flectir o tronco para a frente, mantendo os joelhos em extensão e permite avaliar a simetria da grelha costal e detectar uma eventual rigidez da coluna (Figura 14).

Na radiografia da coluna com incidência postero-anterior, a curva escoliótica mede-se pelo método Cobb: ângulo entre as duas vértebras com maior inclinação relativamente ao sacro. (Figura 15). 


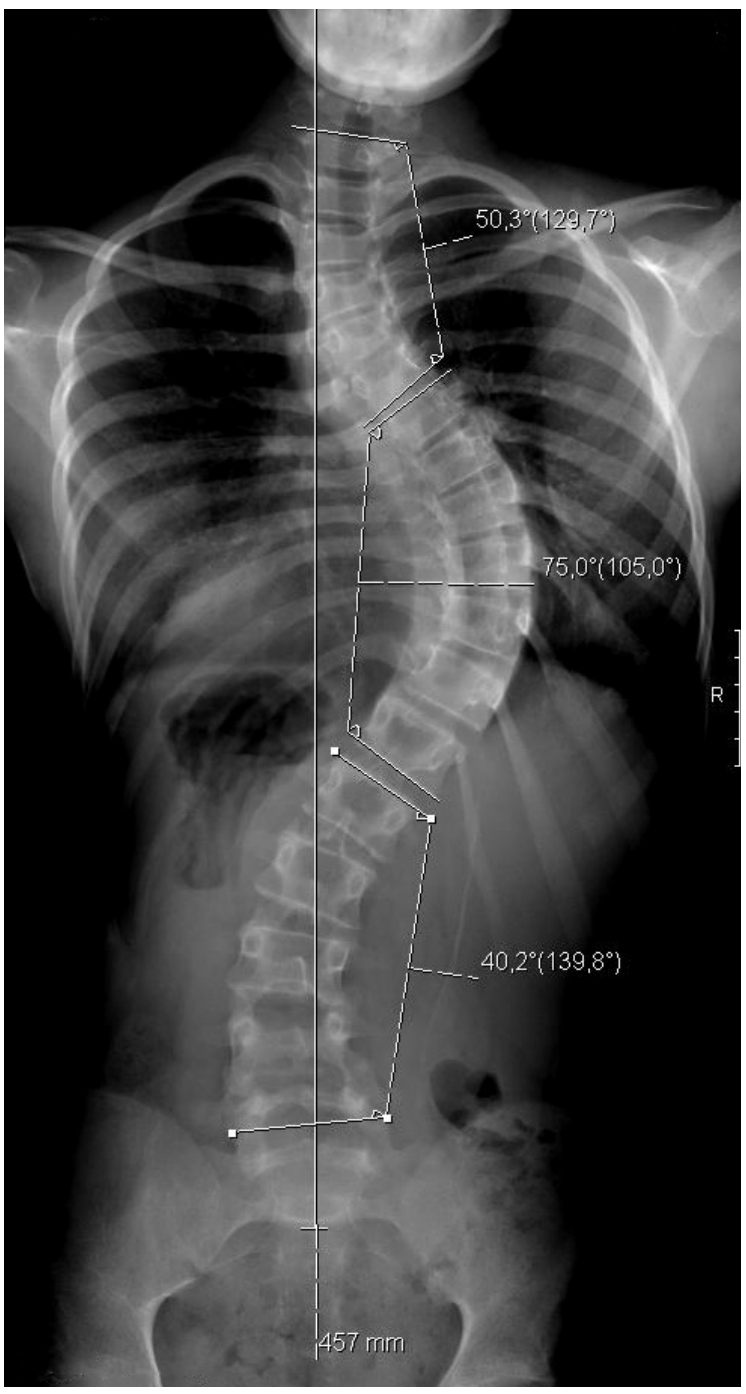

Figura 15. Radiografia de doente com escoliose de curva tripla e medição do ângulo de Cobb em cada curva.

O sinal de Risser, mede a proporção de ossificação da crista ilíaca, permitindo estimar a maturidade esquelética, crescimento residual expectável para a coluna e o risco de progressão da curva. Este risco é mais importante para os graus de Risser 0-1-2, sendo inferior no grau de Risser 3, quando já se observa $75 \%$ de ossificação da apófise ilíaca.
Nos doentes com escoliose a monitorização regular da progressão da curva tem que ser regular, geralmente a cada seis meses. As opções terapêuticas resumem-se a vigilância, ortótese (colete) ou correção cirurgica. Cerca de 90\% das curvas são de pequenas dimensões e exigem apenas monitorização. Está provado que exercícios físicos, estimulação elétrica e técnicas de manipulação são ineficazes e devem ser evitadas.

De uma forma geral, curvas com ângulos de Cobb $<20^{\circ}$, necessitam apenas de observação e curvas $>20^{\circ}$ necessitam de seguimento, sendo que as curvas progressivas com ângulo de Cobb> $25^{\circ}$ em crianças com crescimento residual importante devem ser alvo de aplicação de colete, reservando-se a correção cirúrgica para curvas que excedem os $40^{\circ}$.

\subsubsection{Displasia do Desenvolvimento} da Anca

A Displasia do Desenvolvimento da Anca (DDA) é um termo que descreve um espetro de anomalias anatómicas da anca que podem ser congénitas ou desenvolver-se durante a infância ou adolescência. O espetro da doença engloba desde formas leves, de displasia acetabular a situações graves, como as luxações teratológicas da anca. Estas, ocorrem antes do nascimento e cursam com deformidade grave do acetábulo e fémur proximal.

As estimativas de incidência da DDA dependem dos critérios de diagnóstico. A instabilidade da anca pode ser observada em 0,5 a 1\% das articulações. A DDA ocorre em cerca de 1 a 20:1000 crianças nascidas. Pensa-se que metade das mulheres que desenvolvem coxartrose tem displasia acetabular pré-existente. 


\section{PROTOCOLO DE RASTREIO}

Tem como objectivo o diagnóstico precoce da Displasia de Desenvolvimento da Anca

2) O rastreio é baseado em:

a) Sinais de Instabilidade - Exame objectivo das ancas da criança (e deve ser realizado desde a nascença até á idade da marcha em todas as consultas):

Limitação da Abdução das Ancas

Ortolani +

D Barlow +

b) Critérios de risco:

V. Apresentação Pélvica

V. História de Oligohidramnios

V. História familiar

V. Deformidades congénitas do pé

$\nabla$ Torcicolo congénito

$\nabla$ Síndrome polimalformativo

$\forall$ Assimetria das pregas

3) Criança com exame objectivo SEM sinais de instabilidade das ancas:

a) Sem critérios de risco - Sem indicaçâo para rastreio b) Com critérios de risco - Ecografia das ancas as $6 S$

Criança com exame objectivo COM sinais de instabilidade das ancas: a) Ecografia das ancas

5) Criança com sinais de instabilidade e $>4 \mathrm{M}$ indicação para $\mathrm{Rx}$ Bacia AP

WWw.sPot.PT

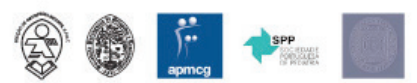

Figura 16. Protocolo de rastreio selectivo da DDA em Portugal, para crianças com factores de risco e sinais de instabilidade da anca.

A etiologia da DDA é multifactorial, podendo existir formas poligénicas hereditárias. A DDA é mais frequente nas meninas, em crianças nascidas de parto pélvico e em crianças com laxidez articular. A anca esquerda é a mais frequentemente afectada.

A displasia acetabular residual é frequente em crianças com DDA e pode ocorrer mesmo após redução precoce e adequada da anca. A dor é mais frequente na adolescência ou idade adulta em doentes com subluxação grave ou quando existe um falso acetábulo.

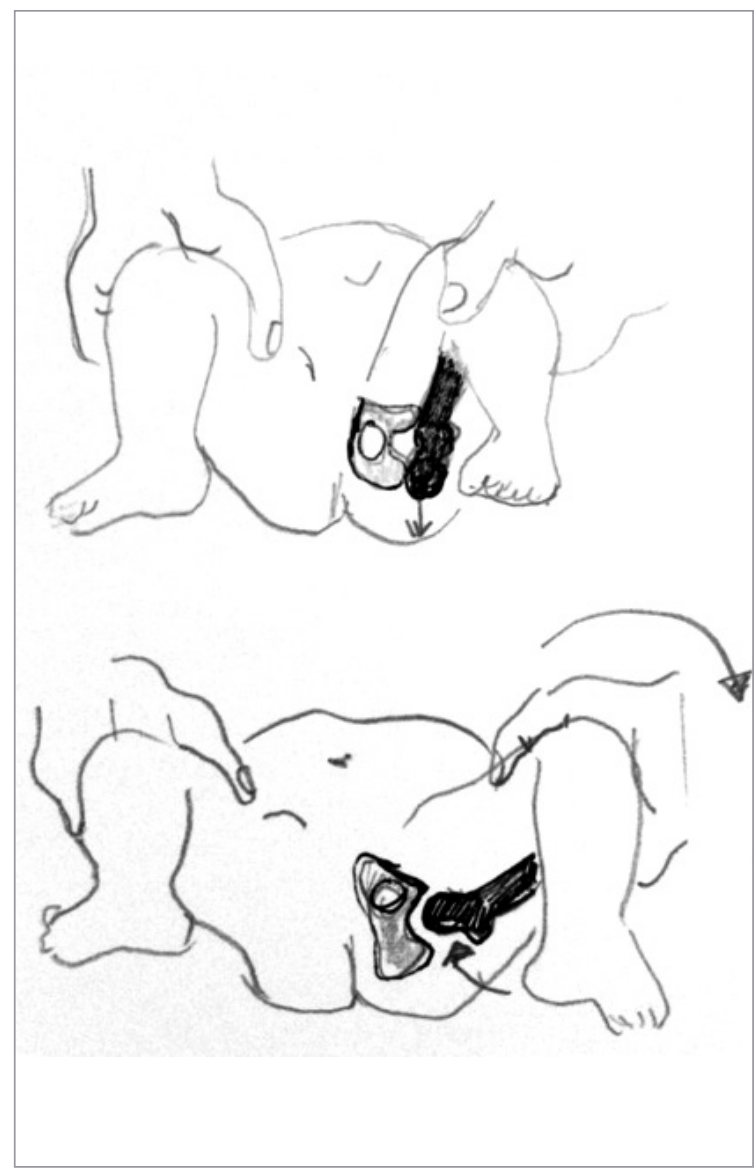

Figura 17. Sinal de Ortolani: é possível sentir um 'clunk', por vezes audível, correspondente à redução da anca.

Reconhecendo que o diagnóstico precoce da DDA é fundamental para um bom resultado, a Sociedade Portuguesa de Ortopedia e Traumatologia e a Sociedade Portuguesa de Pediatria e a Associação Portuguesa de Medicina Geral e Familiar estabeleceram um protocolo de rastreio selectivo da DDA (Figura 16) .

Todos os recém-nascidos devem ser examinados, no sentido de verificar a presença ou ausência de sinais de instabilidade da anca. Os sinais de Ortolani (o observador sente que a 


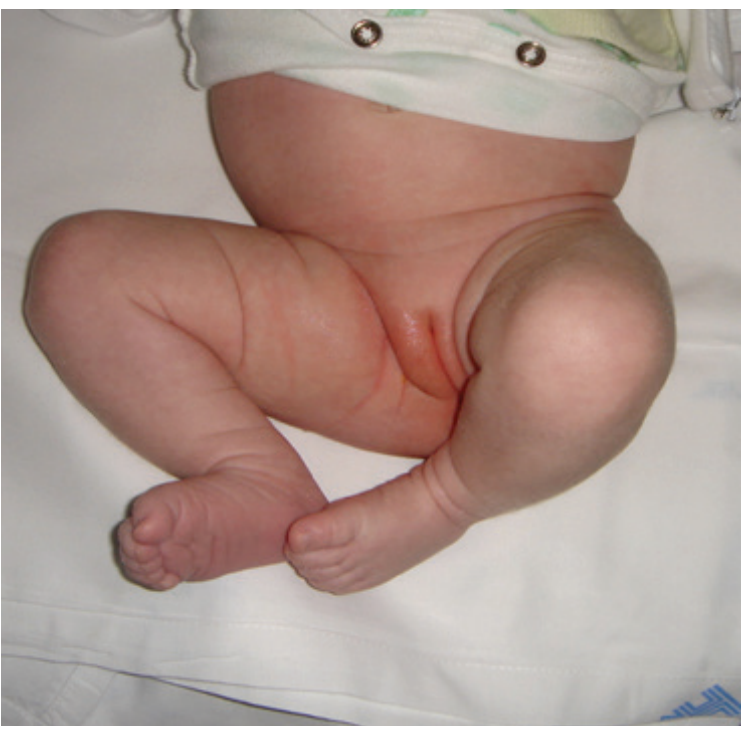

Figura 18A. Limitação da abdução da anca esquerda em lactente.

anca é colocada no acetábulo enquanto realiza manobra de abdução e ligeira tracção da anca em flexão) e Barlow (o observador sente que a anca é luxável quando realiza manobra de adução e pressão em sentido posterior) devem ser pesquisados (Figura 17).

É importante ter a noção de que os sinais de DDA mudam com a idade da criança. A incidência de instabilidade da anca diminui cerca de 50\% na primeira semana de vida. O exame deve ser repetido de forma gentil e suave. A criança deve estar tranquila e confortável. Os sinais clássicos de limitação da abdução da anca e encurtamento do membro (sinal de Galeazzi) aumentam ao longo das primeiras semanas e meses de vida (Figura 18). As luxações bilaterais da anca são as mais difíceis de diagnosticar.

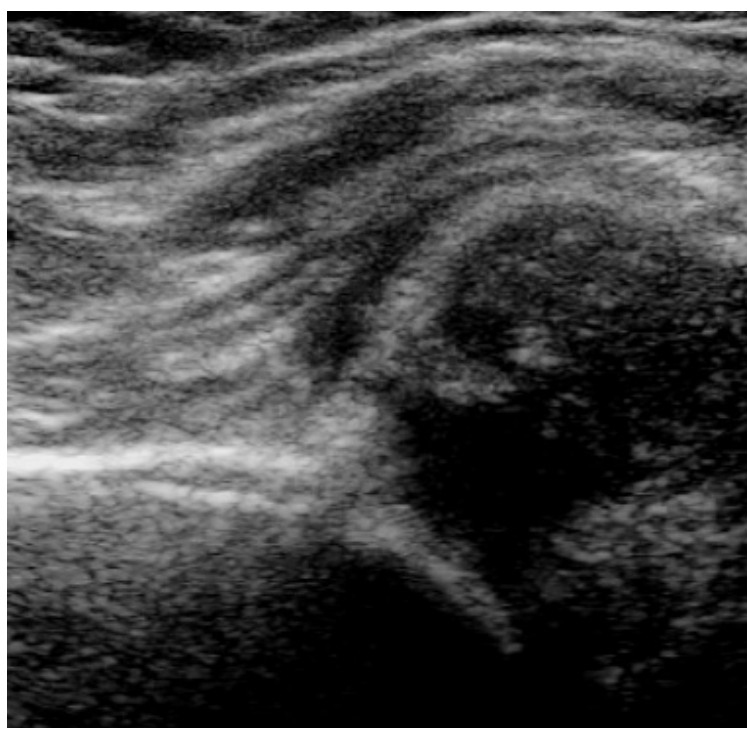

Figura 18B. Ecografia da anca: Luxação da cabeça femoral.

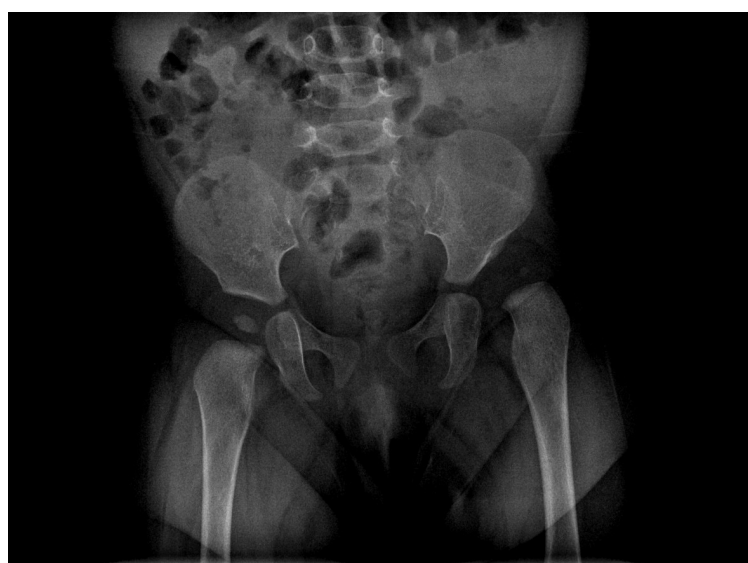

Figura 19. Radiografia da bacia numa criança com luxação da anca esquerda.

Quando estão presentes fatores de risco para DDA, a criança deve ser examinada repetidamente e submetida a um exame imagiológico. A ecografia da anca será o exame de escolha até aos quatro a seis meses de idade (Figura 18B), sendo que, no 


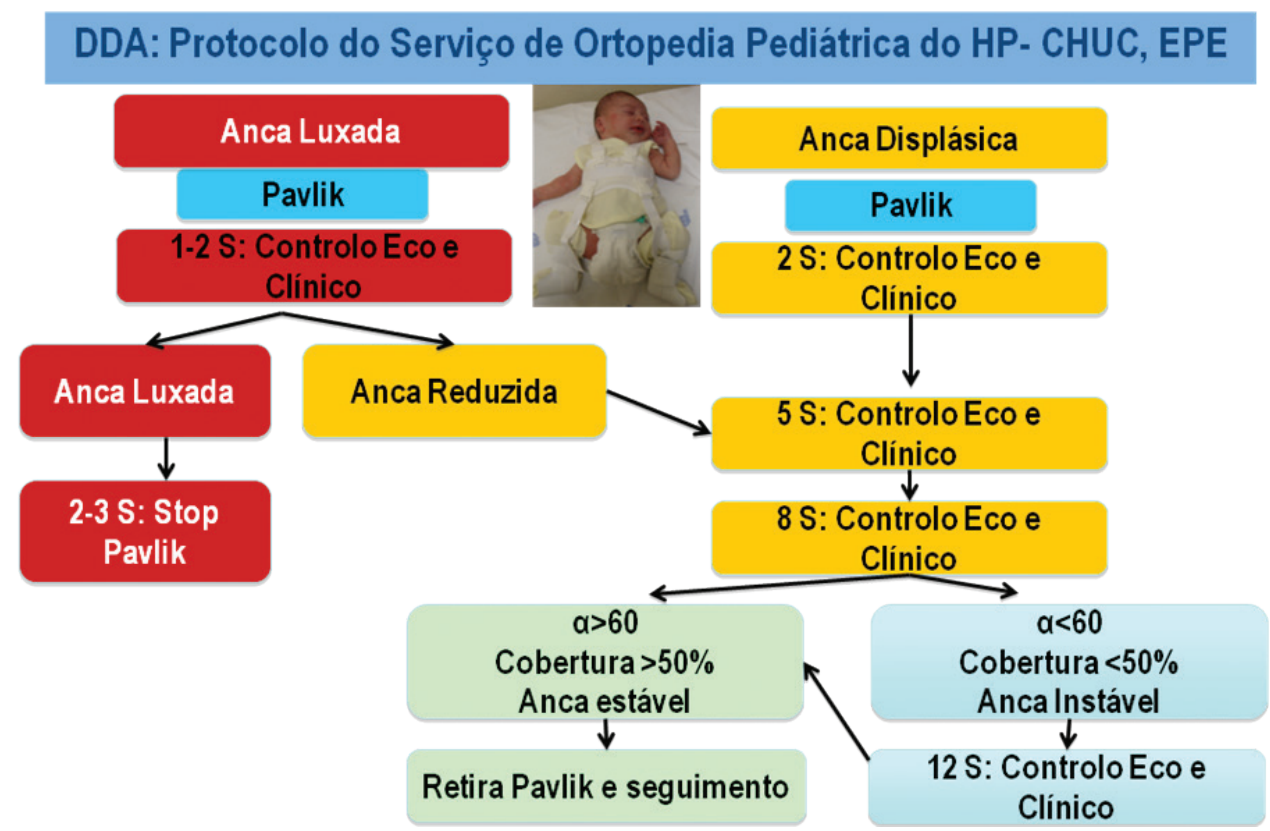

Figura 20. Protocolo de utilização da tala de Pavlik, seguido no Serviço de Ortopedia Pediátrica do Hospital Pediátrico- CHUC.

Hospital Pediátrico de Coimbra, a radiografia é utilizada geralmente só após essa idade e/ou quando a ecografia é de difícil execução ou não permite a visualização adequada de todas as estruturas (figura 19). Numa anca displásica, o ângulo alfa (ângulo entre o ilíaco e o teto acetabular) é inferior a $60^{\circ}$.

$\mathrm{Na}$ abordagem de crianças com DDA, os principais objetivos são o diagnóstico precoce, a redução da luxação, evitar a necrose avascular, e corrigir a displasia residual.

Até aos seis meses de idade, a tala de Pavlik, que permite o movimento em flexão e abdução da anca, pode ser aplicada no tratamento da DDA (Figura 20). É necessário monitorizar a criança clínica e imagiologicamente. Se a anca não estiver reduzida em duas a três semanas, este tratamento deve ser abandonado, para evitar deformidade da cabeça femoral ou fixação da anca em posição que dificulte uma eventual redução fechada ou aberta.

Em crianças com idade superior a seis meses ou falência de tratamento com tala de Pavlik, está indicada a redução fechada ou aberta. No Serviço de Ortopedia Pediátrica do Hospital Pediátrico CHUC, os pais podem escolher entre redução fechada gradual por programa de tracção no arco ou redução sob anestesia geral no Bloco Operatório, com tenotomias do adutor longus \pm psoas e gesso pelvipodálico. Em crianças com idade superior a 18 meses, além da redução aberta, são geralmente necessárias osteotomias do fémur e/ou ilíaco. Se a obtenção de uma redução concêntrica da anca é fulcral, evitar a necrose avascular é de extrema importância, já que esta complicação altera o crescimento femoral proximal, cria deformidade, e leva a artrite degenerativa prematura. 


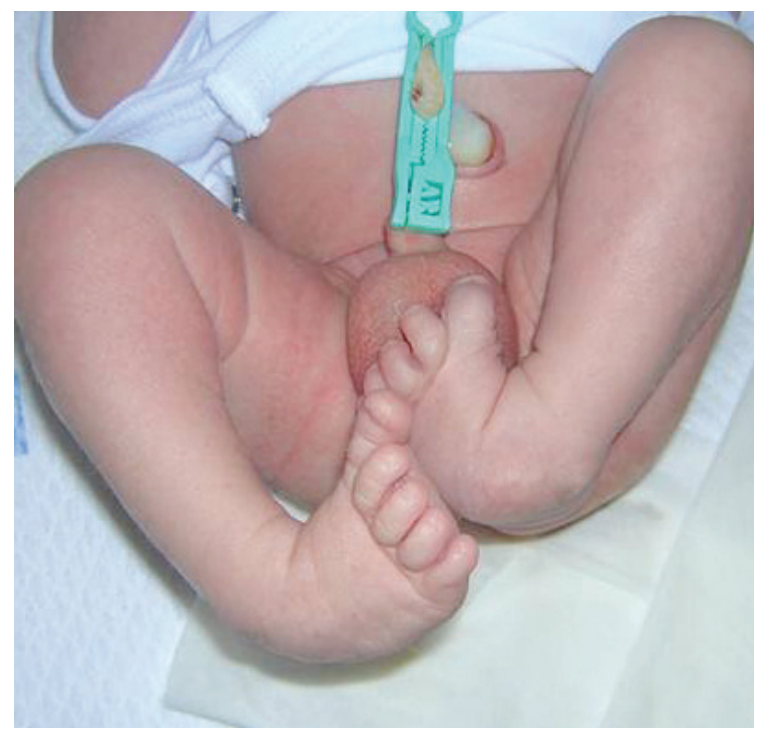

Figura 21. Pé boto bilateral.

Após a cirurgia, a criança deve ser cuidadosamente acompanhada para avaliar o efeito do tempo sobre o crescimento, a redução, e o desenvolvimento acetabular. A frequência de estudos radiográficos é individualizada, de acordo com a gravidade da DDA e a evolução.

\subsubsection{Pé Boto}

O pé boto é uma deformidade congénita complexa que inclui componentes de cavo, aduto, varo, equinismo e rotação medial do pé (Figura 21). A deformidade ocorre em aproximadamente $1 \mathrm{em}$ 1000 nascimentos, é bilateral em metade dos casos, e afeta mais frequentemente o sexo masculino.

A etiologia do pé boto é multifatorial. Pode ser idiopático ou estar associado com outras anomalias congénitas, defeitos do neuro-eixo, anomalias do sistema urinário ou sistema digestivo, e outros problemas músculo-esqueléticos.
O pé boto trata-se preferencialmente pelo Método de Ponseti, sendo a taxa de sucesso superior a $90 \%$ para o pé boto idiopático. A correção gradual é conseguida pela manipulação e engessamento, segundo o Método de Ponseti (Figura 22). O equino é a última deformidade a ser corrigida, geralmente através de uma tenotomia percutânea do tendão de Aquiles. Quando retirado o ultimo gesso, é aplicada uma ortótese de Dennis-Bowne, com duas botas unidas por uma barra, que visa manter o pé corrigido e deve ser mantida durante o periodo noturno até a criança ter cinco anos de idade.

O pé boto deve ser diferenciado do metatarso aduto e varo. Esta é a deformidade mais frequente do pé e caracteriza-se por uma convexidade do bordo lateral do pé. Está associado com a displasia da anca em $2 \%$ dos casos, pelo que é essencial um exame clínico cuidado. 


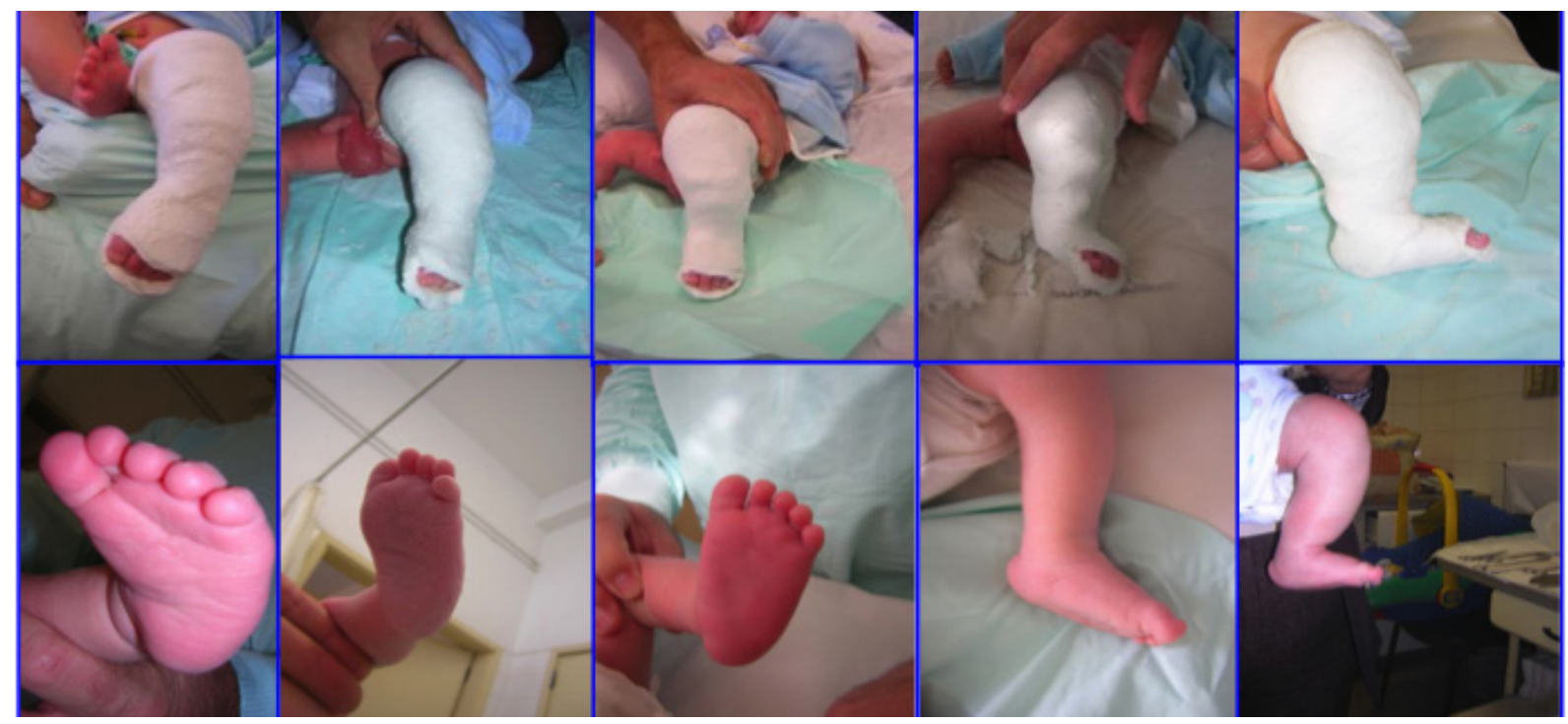

Figura 22. Tratamento do pé boto pelo Método de Ponseti,com gessos sucessivos.

\subsection{FACTOS A RETER}

É essencial que os Médicos que observam Crianças com suspeita de problemas músculo-esqueléticos, saibam diferenciar variantes da normalidade de situações patológicas. Geralmente, a realização de uma história clínica e exame objetivo cuidadosos são suficientes para estabelecer esta distinção e orientar adequadamente a criança e família.

\section{Leitura complementar}

Herring, J. Tachjan's Pediatric Orthopaedics. $5^{\text {th }}$ Edition. Elsevier Saunders. Philadelphia, 2014

Seabra, JF. Ortopedia Infantil: O Fundamental. ASIC. Coimbra, 2016.

Staheli, L. Fundamentals of Pediatric Orthopaedics. $4^{\text {th }}$ Edition. Wolters Kluwer, Lippincott Williams\&Wilkins. Philadelphia, 2008.

Weinstein, S. Lovell and Winter's Pediatric Orthopaedics. $7^{\text {th }}$ Edition. Wolters Kluwer, Lippincott Williams\&Wilkins. Philadelphia, 2014. 